\title{
Clinical evaluation and treatment of insomnia in childhood
}

\author{
Magda Lahorgue Nunes, ${ }^{1}$ Verônica Cavalcante ${ }^{2}$
}

\begin{abstract}
Objectives: The aim of this article is to review and update the knowledge about insomnia in childhood.

Source of data: The text was based on a MEDLINE search (publications from 1999 to 2004) using the keywords sleep disorders, insomnia, and childhood. Classic articles and textbooks about the subject were also included. The authors proposed a practical schedule to evaluate and treat insomnia in childhood.
\end{abstract}

Summary of the findings: The article was structured on descriptive topics containing the definition of insomnia, disorder, age-related clinical characteristics and therapeutics.

Conclusions: Insomnia is a prevalent sleep disorder in pediatric outpatient clinics and is often misdiagnosed. Defining its etiology is the main goal to establish therapeutic procedures. In most cases, clinical history is sufficient to establish the diagnosis and reassure parents of the benign nature of this condition.

J Pediatr (Rio J). 2005;81(4):277-86: Sleep disorders, childhood, insomnia.

\section{Introduction}

Sleep disorders are common in the general population and may affect both adults and children; however, with different clinical manifestations. In general, sleep disorders may be classified into three types: difficulty sleeping, excessive daytime sleepiness and parasomnias. ${ }^{1-3}$ The present article aims to discuss the clinical assessment and management of insomnia in pediatric patients.

1. Associate professor of Neurology and Pediatrics, Medical School, Pontifícia Universidade Católica do Rio Grande do Sul (PUCRS), Porto Alegre, RS, Brazil.

2. Pediatrician and psychotherapist, Instituto Sedes Sapientiae, São Paulo, SP, Brazil.

Manuscript received Mar 01 2005, accepted for publication May 312005.

Suggested citation: Nunes ML, Cavalcante V. Clinical evaluation and treatment of insomnia in childhood. J Pediatr (Rio J). 2005;81: 277-86.
A recent study, which included data on school-aged children, detected sleep disorders in $10.8 \%$ of the interviews; however, less than $50 \%$ of the parents who considered their children to suffer from sleep disorders had discussed this problem with a pediatrician. ${ }^{4}$ These findings may be explained by the fact that parents do not regard sleep disorders as a medical problem and that they often lack knowledge about normal sleep patterns, in addition to the fact that sleep problems are overlooked and underdiagnosed by physicians.

Giving sleep disorders due attention should be a priority in pediatric care, since the persistence of disorders that develop in childhood has been associated with behavioral and emotional disorders at school age and in adolescence. 4,5

Insomnia is defined as the difficulty falling or staying asleep and is characterized by different aspects during its development. In childhood, besides the reduction in total 
sleep time, there is some discrepancy between a child's sleep requirements and the pattern established by the family. ${ }^{1-7}$ Insomnia may affect healthy children or be secondary to several organic and emotional disorders. The identification of what is causing insomnia is the first step towards an adequate approach, since this situation has specific and different characteristics in children and adolescents, which causes its management to differ from that often used in adults.

There is a paucity of studies in the medical literature especially designed to assess the prevalence of insomnia in pediatric patients. However, some authors suggest that primary insomnia may cause $3-41 \%$ of sleep disorders in children. $5,8-10$

The aim of this study is to discuss the clinical features, investigation, and management of insomnia in pediatric patients through the critical review of the literature.

\section{Sleep organization and normal sleep pattern from the neonatal period to adolescence}

Sleep organization varies remarkably from the neonatal period to adolescence. ${ }^{6,11-16}$ In newborns, the sleep cycle follows the ultradian rhythm ( $<24$ hours, regardless of night/day), and in the first months of life, the circadian rhythm begins to consolidate (equivalent to 24 hours, dependent upon night/day). At birth, newborns have 3-4 hours of continuous sleep alternated with more or less one hour of wakefulness. This rhythm is continuous, regardless of the external environment, i.e., day/night. ${ }^{15}$

During the first month of life, the sleep-wake cycle starts to adapt to the night-day cycle. At the end of the first month of life, the night sleep periods last longer. ${ }^{13}$

Important structural changes occur in sleep architecture during the third month of life. At this age, the longest nonstop sleeping period does not exceed 200 minutes and around the sixth month it does not last longer than 6 hours. Night is divided into two continuous sleep periods, alternated with an awakening period. During the day, wakefulness is consolidated, but it is still interrupted by daytime napping. Between the ninth and tenth months, infants sleep on average 9-10 hours every night (with interruptions) and 23 hours a day divided into two naps. At 12 months, night sleep should be consolidated, but daytime naps are maintained. 13,14

Between the second and third years of life, long periods of night sleep persist, still followed by one or two daytime naps (in the middle of the morning and at the beginning of the afternoon) that last shorter, not exceeding two hours. At the age of three, only afternoon naps often occur. Night sleep occurs in a cycle that alternates between NREM (quiet sleep with non-rapid eye movements) and REM (active sleep with rapid eye movements). Short periods of partial or total wakefulness may occur and are perfectly normal, and in this case, children go back to sleeping spontaneously. From this age on, children reach an adult's percentage of REM sleep, spending $25 \%$ of their time sleeping. ${ }^{12-14}$
By the age of five, night sleep should be totally consolidated, without night awakenings or the need for daytime naps. ${ }^{12-14}$ Only between 5 and 10 years does total night sleep time gradually decrease. ${ }^{16}$

In pre-adolescence, between the ages of 11 and 13, night sleep lasts around nine hours/night. In adolescence, the duration of night sleep tends to decrease (mean of seven hours), ranging from 8.6 to 6.4 between the ages of 14 and 16. ${ }^{16}$ There is a difference in sleep habits between school days and weekends, and an increase in total sleep time during the weekends as a way to make up for sleep deprivation on school days. ${ }^{12}$

\section{Causes of insomnia}

According to the International Classification of Sleep Disorders, insomnia is a type of dyssomnia, which is subdivided into intrinsic dyssomnias (narcolepsy, obstructive sleep apnea syndrome, restless legs syndrome and psychophysiological insomnia) and extrinsic dyssomnias (insomnia caused by acute stress or environmental change, limit-setting sleep disorder, sleeponset association disorder, excess intake of fluids or nocturnal eating, inadequate sleep hygiene, circadian rhythm sleep disorders). 6

Characterization of insomnia depends on the individual standards according to each child's sleep requirement, age, and daily activities. ${ }^{17}$ It has been argued in the literature whether the classification of insomnia as a dyssomnia proposed by the American Sleep Disorders Association ${ }^{6}$ (ASDA) can be applied to pediatric patients. Some authors prefer to classify it as protodyssomnia, a definition that is based on the context of the child as a developing being. ${ }^{18}$ In our opinion, the definition of childhood insomnia as the difficulty falling asleep or multiple awakenings during the night, outside the physiological pattern expected for each age, is more didactic and easier to apply.

The most common causes of childhood insomnia are described in Table 1, which, for teaching purposes, are presented in order of their occurrence according to each age. 1,3

Organic disorders (both chronic and acute) may cause insomnia. Acute diseases often cause insomnia that is related to the onset of the problem, having its duration restricted to the length of the disease. Among the most common examples are respiratory diseases, fever, otitis, traumas, teething, milk allergy, gastroesophageal reflux, etc. ${ }^{1,7}$

Chronic diseases may cause insomnia through different mechanisms and their accurate diagnosis is imperative for implementation of proper treatment. Table 2 shows the clinical features and the mechanisms of some chronic diseases associated with childhood insomnia. 19-27

Insomnia is more frequently caused by environmental and behavioral changes or psychological factors, which are discussed next. 
Table 1 - Causes of insomnia according to age range

\begin{tabular}{|c|c|}
\hline Age range & Cause \\
\hline Newborns & $\begin{array}{l}\text { Sleep-onset association disorder } \\
\text { Gastroesophageal reflux or other chronic or acute diseases } \\
\text { Inadequate and excessive intake of fluids or foods at night }\end{array}$ \\
\hline $2-3$ years & $\begin{array}{l}\text { Inadequate and excessive intake of fluids or foods at night } \\
\text { Milk allergy } \\
\text { Chronic or acute diseases }\end{array}$ \\
\hline $\begin{array}{l}\text { Pre-school and } \\
\text { school age }\end{array}$ & $\begin{array}{l}\text { No limit-setting } \\
\text { Fear, nightmares } \\
\text { Restless legs syndrome } \\
\text { Obstructive sleep apnea syndrome } \\
\text { Other chronic or acute diseases }\end{array}$ \\
\hline Adolescence & $\begin{array}{l}\text { Delayed sleep phase } \\
\text { Individuality (early riser versus late riser) } \\
\text { Anxiety } \\
\text { Family or school presure } \\
\text { Emotional disorders (anorexia, schizophrenia, mania) } \\
\text { Restless legs syndrome } \\
\text { Obstructive sleep apnea syndrome } \\
\text { Other chronic or acute diseases }\end{array}$ \\
\hline
\end{tabular}

Fear and anxiety are frequent causes of insomnia.4,28 Infants may have varied degrees of stress after separation from their mothers, causing difficulty falling asleep. Fear is more common among children aged 2 or 3 years. Fear of being alone may be associated with movies or stories, with arguments between mother and father, exposure to violent movies or stories, or with any other frightening event. This situation is seldom a result of the child's

Table 2 - Chronic disease and insomnia

\begin{tabular}{|c|c|c|}
\hline Disease & Signs/Symptoms & Mechanism \\
\hline Visual impairment & $\begin{array}{l}\text { Insomnia, tiredness } \\
\text { and excessive day naps }\end{array}$ & $\begin{array}{l}\text { Biological alteration, } \\
\text { free circadian rhythm }\end{array}$ \\
\hline Mental retardation & $\begin{array}{l}\text { Fragmented sleep periods } \\
\text { during day and night }\end{array}$ & Alteration in the sleep pattern \\
\hline Autism & $\begin{array}{c}\text { Immature sleep pattern, architecture } \\
\text { non compliant with chronological age, } \\
\text { insomnia, early awakenings }\end{array}$ & Alteration in the sleep pattern \\
\hline Tourette's syndrome & $\begin{array}{l}\text { Nocturnal restlessness } \\
\text { and fragmented sleep }\end{array}$ & $\begin{array}{l}\text { Reduction of REM sleep, \% increase of } \\
\text { NREM sleep phases III-IV }\end{array}$ \\
\hline Neuromuscular diseases & Irritability and day sleepness & $\begin{array}{l}\text { When respiratory muscles are involved, } \\
\text { there area hypoventilation and nocturnal apneas }\end{array}$ \\
\hline Epilepsy & Fragmented sleep & $\begin{array}{l}\text { Nocturnal crises according to the type } \\
\text { of epilepsy with sleep-vigilance cycle, } \\
\uparrow \% \text { NREM phase I-II and } \downarrow \text { phases III, IV }\end{array}$ \\
\hline Asthma & Fragmented sleep & $\begin{array}{l}\text { Crises exacerbate at night for circadian variation } \\
\text { of the pulmonary function }\end{array}$ \\
\hline OSAS & $\begin{array}{l}\text { Fragmented sleep at night, } \\
\text { several awakenings, } \\
\text { excessive day sleepness }\end{array}$ & $\begin{array}{l}\text { Partial or complete obstruction } \\
\text { of upper airways during sleep }\end{array}$ \\
\hline
\end{tabular}

REM = rapid eye movement $;$ NREM = non-rapid eye movement ; OSAS = obstructive sleep apnea syndrome . 
psychosocial deterioration. 4,29 Losing a parent or sibling and posttraumatic stress are frequently associated with sleep disorders in children, and so are problems at institutions (day care center, school, club), as well as physical or sexual abuse/violence. ${ }^{28,29}$ Depression and anxiety are frequent causes of insomnia among adolescents and pre-adolescents. ${ }^{3,31}$

Insomnia secondary to habits and inadequate associations is characterized by the necessity of receiving external stimuli in order to fall asleep, such as being lulled or rocked, tapped on the back, or lying on the lap. In periods of nocturnal physiological awakenings, children cannot go back to sleeping spontaneously and need the same sleepinducing measures, requiring intense and repeated involvement of the parents during the night. ${ }^{32}$

Insomnia associated with inadequate and excessive intake of fluids or foods at night occurs due to the conditioned feelings of hunger or thirst during the night. At 6 months, except for the case of preterm newborns, infants do not have to be fed during the night. When breastfeeding is maintained, more awakening episodes tend to occur. ${ }^{1,9,11}$

Limit-setting insomnia may occur after infants develop motor skills that allow them to leave the cradle and when parents refrain from controlling the nocturnal activities of their infants. ${ }^{11}$ Limit-setting problems are mostly related to parents, who cannot set limits, harbor a feeling of guilt, psychological problems, alcoholism, maternal depression, family stress. This situation may also be associated with children's intrinsic problems as occasional secondary reward. This diagnosis involves understanding the normal sleep/ wake patterns at different ages. One of the most frequent problems is related to establishing an early bedtime, in a period in which the child is fully active, making children lie sleepless in bed (according to their internal rhythm it is too early to go to sleep). ${ }^{11,33,34}$

It has been observed that preschool children who are used to sharing their parent's bed have more sleep disorders (frequent awakenings, difficulty falling asleep) and behavioral problems (less ability to adapt). ${ }^{33}$

Sleep disorders due to lack of routine/limits tend to intensify during the transition period between childhood and pre-adolescence and adolescence. This occurs because youngsters become more independent and parental control is not that strong, especially on weekends. ${ }^{34}$

Circadian rhythm sleep disorders, called delayed sleep phase syndrome, often occurs in adolescents. It starts out with the tendency to go to bed later every night (on weekends or vacations) and to wake up later as well. This situation often results from physiological changes in the circadian rhythm during puberty. The initial symptoms are difficulty awakening at the desired time and afternoon naps after school.3,11,35 It is of paramount importance that, when evaluating adolescents with sleep disorders, their individuality be taken into account (early riser versus late riser), possibility of total sleep deprivation (often associated with delayed sleep phase combined with strict school time) and insomnia secondary to emotional disorders. 35,26
The restless legs syndrome is an autosomal dominant disease of unclear etiology, characterized by unpleasant sensations in the legs. This provokes an uncontrollable urge to move when at rest, causing sleep disturbance. ${ }^{6}$ A recent study revealed that infants may have these symptoms in their first year of life, but the definitive diagnosis, obtained through polysomnography, is usually postponed due to failure to identify the problem. 37

Parasomnias, sleep disorders characterized by motor and/or behavioral changes associated with partial awakening, can also cause sleep interruptions because of sleepwalking, confusional arousal, night terror, bruxism, etc. $7,18,19$

When evaluating the etiology of insomnia, we have to learn how to investigate and give proper attention to emotional aspects in a systematically fashion as we do with organic aspects. The diagnosis of psychological situations should not be made by exclusion (in a passive manner). Psychological diagnosis has to be as active as the organic one. Pediatricians must be able to understand that sleep disorders may constitute symptoms related to children's internal or external world or to their families. It is common knowledge that, among psychiatric disorders, anxiety is strongly correlated with childhood sleep disorders. 19,38

Initially, pediatricians should be able to establish the differential diagnosis with anxiety. ${ }^{39}$ This diagnosis is subdivided into situational, existential and pathological anxiety. Situational anxiety is that which occurs in several human experiences, such as diseases, wars, catastrophes, death of loved ones, choice of an educational method for one's children, among others. Existential anxiety is characterized by situations which move us away from our goals in life, i.e., from what we want to become. They seldom occur in children; however, there are some cases in which expectations from the family and society produce anxiety in children. ${ }^{39}$ Pathological anxiety is caused by twisted reality based on a reference of one's internal world. 39

\section{Insomnia and other comorbidities}

Sleep disorders often affect children with psychiatric disorders. Insomnia may occur in approximately two thirds of pediatric patients with depression and is usually one of the initial symptoms of this clinical picture. In bipolar disorder, there is a remarkable reduction in the necessity to sleep. In cases of abuse or posttraumatic stress, there is difficulty falling and staying asleep and there are frequent nightmares. ${ }^{38}$

The association between sleep disorders and anxiety/ depression in children has been clearly observed (with an odds ratio of 6.9) in a cohort study of newborns who were assessed between the ages of 6 and 11 years. ${ }^{31}$

The consumption of illicit drugs in adolescence, a growing public health problem in the Brazilian society, may cause sleep disorders. Insomnia is a frequent finding among adolescents who abuse alcohol, other illicit drugs, nicotine and caffeine. ${ }^{38}$ Pharmacological drugs such as 
bronchodilators, antidepressants and stimulants can also lead to insomnia. ${ }^{19}$

The association between sleep disorders and attention deficit hyperactivity disorder (ADHD) is well established and may be found in approximately $50-60 \%$ of the cases. Children with this disorder show fragmentation and difficulty falling asleep. ${ }^{40}$ Early signs of ADHD include sleep disorders during the breastfeeding period. ${ }^{41}$

Comorbidity between insomnia and headache has been observed in adults and in children. ${ }^{42,43}$

\section{Management of insomniac children}

When families seek medical help because their children cannot sleep, the children's physical condition must be investigated in order to rule out this possibility. But in the very first appointment, anamnesis should be as complete as possible, considering that children are body and mind and that everyday personal and family experiences have a strong influence on their behavior, and sleep is a way to express them. ${ }^{1-3,7}$

Management of insomnia must follow an investigation protocol. ${ }^{7,43-47}$ Based on the literature and on our personal experience, and in order to facilitate understanding, we suggest dividing the management of insomnia into steps. In clinical practice, these steps are interdependent and often associated 7,43-47 (Table 3).

\section{Step 1 - Diagnostic routine for defining the cause of insomnia}

To establish the diagnosis of insomnia it is necessary to collect information related to the problem, which should include the children's sleep habits, bedtime rituals, associations used to induce sleep and 24-hour sleep/wake cycle. After that, specific information about the sleep disorder should be collected, as well as its clinical description, characteristics related to its onset and possible associations, in addition to information about the environment where children sleep. The family's psychosocial profile and family history of sleep disorders should be approached. Traditional anamnesis and physical examination should be performed in order to rule out organic disorders (either chronic or acute) that may trigger the sleep disorder. ${ }^{7,47}$

\section{Step 2 - Direct treatment or elimination of the cause of insomnia}

In case of chronic or acute diseases, the cause must be treated. When environmental factors that cause insomnia are identified, they should be corrected or eliminated (see sleep hygiene).

\section{Step 3 - Sleep hygiene}

Sleep hygiene means the establishment and maintenance of adequate conditions for healthy and effective sleep. This process involves a series of behaviors and environmental factors that per se may solve most cases of insomnia. ${ }^{46}$ Guidelines for sleep hygiene should be discussed with the parents, from the very first months of life, during routine visits. In most cases, this measure prevents the development of sleep disorders. An adequate sleep hygiene is based on three major aspects: environment, schedule, and activities before bedtime. The sleep environment should be dark or dim, quiet, and have an adequate temperature (avoid cold or overheating). Bedtime and waking time must be consistent and regular. Napping time during the day must be age-appropriate and always regular and consistent. The routine sequence of activities before bedtime must be consistent (e.g.: taking a bath or shower, having dinner, toothbrushing, putting on the pajamas, using the toilet, playing soothing music or telling pleasant stories). Putting children to bed must also be consistent, and in this case, transitional objects may be used (e.g.: a toy, doll, favorite diaper, etc). Strenuous physical activities must be avoided before bedtime, as well as TV programs or stories that may frighten the children. Before putting the children to bed, make sure they are sleepy. ${ }^{2}$ The maintenance of routines

Table 3 - Management of insomnia

\begin{tabular}{ll}
\hline Phase & Description \\
\hline 1 & Diagnostic routine for defining the cause of insomnia \\
2 & Direct treatment or elimination of the cause of insomnia \\
3 & Sleep hygiene \\
4 & Behavioral approach \\
5 & Drug therapy* \\
\hline
\end{tabular}

* In refractory cases, phases 3, 4 and 5 are associated. 
and establishment of limits help children synchronize their circadian rhythm with that of the family environment. ${ }^{11}$

When anamnesis suggests inadequate sleep habits and associations, such as children who need direct stimuli from their parents in order to fall asleep, parents should be prepared to gradually make their children sleep in their own bed by using transitional objects and by minimizing the necessity of external intervention. When children are taught to sleep by themselves, if they wake up in the middle of the night, they tend to go back to sleeping on their own; otherwise, their parents will have to stay with them until they fall asleep. ${ }^{32}$

When insomnia is related to age-inappropriate nocturnal eating habits, the solution is to slowly reduce the offer of food at night so that this habit can be eliminated. ${ }^{11}$

In cases of fear and anxiety, the main objective is to spot the cause and eliminate it, followed by attempts to make children get used to sleeping by themselves. Changing bedtime for when children feel sleepy might also do the trick. ${ }^{30,31}$ In situations in which the pediatrician needs to refer the patient to another professional, he/she must clearly state the suspected diagnosis and his/her limitations in dealing with the problem, so that the referral can be successful. ${ }^{39}$ It is not acceptable that the reason for referral be based on the principle that what is not organic must be psychological. For instance, in case of purely organic diagnosis, sometimes more than one appointment is necessary to establish the complete diagnosis of a sleep disorder. In our opinion, with regard to situational and existential anxiety, pediatricians themselves can treat the problem successfully. To do that, they should be willing to receive and listen to family members and the child.

In cases of delayed sleep phase syndrome, which usually occurs in adolescence, sleep time should be gradually stabilized by having the patient go to bed 15 minutes earlier every night until he/she finds a sleep time that is compatible with his/her daily activities. ${ }^{1,3,11}$ Sleep/ waking time should be kept as stable as possible, even on weekends. Caffeine intake should be avoided. 44

\section{Step 4 - Behavioral approach}

The behavioral approach to childhood insomnia has been largely discussed and several studies have been published about this topic in the last few years. $44,45,48,49$ After the second year of life, when it is possible to establish a reward system with children, this technique proves very efficient; before this time, its use and efficiency are still controversial.

The behavioral approach is based on the understanding that sleep disorders involve the diagnosis of children and of their families. The following programs may only be used in children who do not suffer from acute diseases and who do not have chronic diseases that affect sleep.
Techniques to be carried out by parents under the guidance of a pediatrician $44,45,47$

a) Systematic extinction: this procedure starts with a short pre-sleep routine and by putting the child to bed at the preset time. Parents say good night and leave the room, ignoring crying and protests, and should not return until the next morning (except if they think the child is in danger). The advantage of this method is its quick response, usually after the third night, if parents maintain a firm attitude. The disadvantage is the difficulty parents have in ignoring the child's crying and not re-entering the room.

b) Systematic extinction with minimal parental check: this procedure is similar to the previous one, however, here parents may check whether the child is okay every 5-10 minutes if he/she does not stop crying. Intervention should be brief (arranging the covers, reassuring that everything is fine, caressing the child's head). The advantage here is that parents feel more comfortable, and the disadvantage is that the child often cries louder when parents re-enter the room.

c) Gradual extinction: this involves establishing pre-sleep routine and bedtime, putting the child to bed and leaving. Set a minimum time period before returning to the bedroom if the child does not stop crying (at least three minutes on the first night), go back to the room, but interact as little as possible, go out and only return after three minutes. Increase the waiting interval every night.

d) Systematic ignoring with parental presence: the presleep routine is similar to the previously described techniques; however, one parent stays in the child's bedroom, lying on a separate bed until the child stops crying and falls asleep. The parent can then return to his/her bedroom. If the child awakens again, the parent should return to the child's bedroom and lie down on a separate bed, without interacting at all with the child. It is important that the child perceive the presence of one parent in the bedroom; for that reason, there should be some illumination. The advantage of this program is that it reduces parent's anxiety and child's crying. It is recommended for children whose insomnia is caused by separation anxiety. The disadvantage is that some parents are reluctant to change their own sleep habits.

e) Gradual systematic ignoring: parents have to calculate the time they will be with the child after each awakening episode until he/she falls asleep. This time should be gradually reduced. This program is recommended for those parents who prefer a more gradual approach.

f) Systematic extinction or ignoring: parents enter the room when the child starts to cry, check whether everything is $\mathrm{OK}$, change diapers if necessary, do not take the child out of bed, leave the room and ignore persistent crying episodes.

g) Modified extinction: consists in ignoring the child's crying/waking for 20 minutes, entering the room to 
check whether there is a real problem, not interacting with the child and leaving. It should take the parent 20 more minutes to return to the child's bedroom.

h) Scheduled awakening: Parents partially awake the child with minimum stimulation just before his/her spontaneous awakening, letting the child go back to sleeping again spontaneously.

i) Bedtime reorganization: a preset bedtime should not be imposed. The child's average sleep time should be observed and then reduced by 15 minutes every three days until the child falls asleep spontaneously at a time that concurs with the family routine.

The behavioral approach techniques applied by the parents are effective in the short and long run. Apparently, there is no significant difference between them; therefore, the selection of the technique should be based mainly on parent's acceptance and compliance. ${ }^{48}$

A recent meta-analysis comparing the studies that employed behavioral approach for the treatment of childhood insomnia revealed that the success of the technique depends on parent's understanding and compliance. ${ }^{49}$

\section{Therapies carried out by qualified professionals}

a) Psychotherapy: highly indicated when sleep disorders are associated with pathological anxiety. It allows establishing a systematic self-discovery process that triggers and speeds up psychological development. ${ }^{39}$

b) Cognitive behavioral therapy (CBT): It is based on the cognitive model (cognitive function that involves inferences about personal experiences and about the occurrence and management of life events) and deals with the hypothesis that an individual's emotions and behavior are influenced by his/her perception of events. There are three cognitive levels: automatic thought, intermediate beliefs and core beliefs. It equates patient's distortions, determining the therapeutic strategies to be used. ${ }^{50}$ As insomnia is mostly associated with negative or inappropriate thoughts, cognitive reorganization may help analyze the thoughts that interfere with sleep. ${ }^{44}$ This technique has been successfully used for the management of insomnia in adults and is recommended by the American Academy of Sleep Medicine, showing a seemingly higher efficiency than other nonpharmacological techniques. ${ }^{51-53}$ The experience of CBT in the management of childhood insomnia is still limited; however, it has been successfully used for the management of anxiety. ${ }^{54}$ CBT includes classic conditioning techniques, operant conditioning, cognitive techniques, behavioral techniques and social learning techniques. ${ }^{55}$ CBT must be performed by a qualified professional with expertise in the area and in pediatric management.

\section{Step 5 - Drug therapy}

Drug treatment of childhood insomnia is quite limited. The drugs used for the management of adult insomnia belong to the group of benzodiazepine and nonbenzodiazepine (e.g.: zolpidem, zaleplon and zopiclone) hypnotic substances. These drugs are not indicated for use in children and there are no studies showing their efficacy or safety in pediatric patients. ${ }^{56,57}$ Nevertheless, the high prevalence of drug therapy in insomniac children, detected by a Spanish study (around $56 \%$ of the sample) is remarkable. ${ }^{57}$

The use of alternative drug therapy, based on the extract of natural, sleep-inducing plants, such as valerian, passiflora and amino acids (5-hydroxytryptophan) has been anecdotally described in isolated cases. ${ }^{58}$ However, controlled studies showing its actual efficacy and safety have not been conducted so far.

Drug therapy for the management of childhood insomnia should be used in very well selected cases after the cause of insomnia has been clarified, and as adjuvant to some of the other behavioral techniques described above. The available options for this age group are restricted to two groups of drugs: antihistamines or chloral hydrate, which should be administered temporarily within the first three weeks of the use of behavioral techniques. 7,47

Antihistamines most commonly used in controlled studies available in the literature are diphenhydramine $(0.5 \mathrm{mg} / \mathrm{kg})$ trimeprazine (30-60 mg/ day) or niaprazine. 56,57 Side effects (sedation, thirst) must be taken into account when prescribing these drugs.

Chloral hydrate is a hypnotic sedative often prescribed for adults and children. It can be given either orally or rectally in doses of $25-50 \mathrm{mg} / \mathrm{kg} /$ dose. Overdosage can cause respiratory depression and arrhythmias. ${ }^{56}$ Its chronic use is totally contraindicated.

Tricyclic antidepressants (imipramine) seem to be efficient in treating insomnia associated with ADHD, whereas serotonin reuptake inhibitors (fluoxetine) are indicated for insomnia associated with Asperger's syndrome or obsessive compulsive disorder (OCD). ${ }^{57}$

In children with insomnia and headache, the use of clonidine $0.025-0.075 \mathrm{mg}$ at bedtime has been described as efficient. 42

Clonazepam, a benzodiazepine agent, is indicated for the management of insomnia caused by parasomnias with partial awakening (night terror, confusional arousal) in the dose of $0.25-0.50 \mathrm{mg} .56$

The release of melatonin, an organic substance produced by the pineal gland, is controlled by an endogenous system synchronized with the external environment (light/day). Organic melatonin levels are high in the dark and low in the light. Its synthesis, available in oral formulation, is a therapeutic option for the treatment of insomnia in adults, and may also be used in healthy children and also in children with neurological deficiencies. ${ }^{59}$ In a recent study, melatonin in the dose of $5 \mathrm{mg} /$ day was efficient in mitigating the symptoms of insomnia in children aged between 6 and 12 years. 60

Table 4 summarizes the recommendations/options of drug therapy against insomnia.42,56-60 
Table 4 - Drug therapy against insomnia

\begin{tabular}{ll}
\hline Drug & Indication \\
\hline Antihistaminic & Healthy children, in association with behavioral therapy. \\
Chloral hydrate & Healthy children, in association with behavioral therapy. \\
Melatonin & Healthy children, in association with behavioral therapy \\
& or children with neurologic or sight problems. \\
Valerian, passiflora, 5-hydroxy tryptophan & Healthy children, in association with behavioral therapy. \\
Imipramine & In children with ADHD \\
Fluoxetin & In children with OCD or S. Asperger \\
Clonidine * & In children with associated headache \\
\hline
\end{tabular}

* A few experiences reported on the literature.

$\mathrm{ADHD}=$ attention deficit hyperactivity disorder; $\mathrm{OCD}=$ obsessive compulsive disorder.

Controlled studies, with a long-term follow-up period, on the management of insomnia in pediatric patients are rare. The review of the literature suggests that drug therapy in childhood is only efficient in the short run, and that behavioral interventions, performed by a qualified therapist, are more effective than drug therapy in the short or long run. 44,57

\section{Overview of the effects of insomnia on neurocognitive functions}

Quite recently, there has been an intense and wideranging discussion in the media about the influence of sleep disorders on neurocognitive functions. Children who have difficulty falling sleep or who have a disturbed sleep seem to present a higher incidence of behavioral disorders (anxiety, hyperactivity, depressive symptoms). ${ }^{61}$ Children with attention deficit complain more frequently of sleep disorders. ${ }^{40}$ The results of these studies, due to the limitations of their design, should be viewed cautiously. ${ }^{61}$

Several studies with children who suffer from obstructive sleep apnea syndrome have demonstrated that leaving this condition untreated causes significant systemic disorders such as pulmonary hypertension and high blood pressure, as well as behavioral disorders (hyperactivity) and learning disabilities. 16,17

Our conclusion is that sleep disorders are not regarded by parents as a medical problem. Routine pediatric anamnesis does not usually include sleep-related problems, and this may occur due to the attention and training these problems fail to receive at medical school. Pediatricians have to know about the normal sleep patterns for each age and be careful not to overestimate the complaint, since it often results in unnecessary exams, medications, and referrals to specialists. Insomnia is a constant complaint among children and should always be given due attention, as it may signal clinical and behavioral problems that will certainly play a role in child development. Since it can affect from infants to adolescents and because it has different clinical manifestations, underdiagnosis is quite frequent. The proper identification of symptoms and etiologic diagnosis allow for an appropriate and individualized management.

\section{References}

1. Ferber R. Childhood sleep disorders. Neurol Clin. 1996;14: 493-511.

2. Blum NJ, Carey WB. Sleep problems among infants and young children. Pediatr Rev. 1996;17:87-93.

3. Sheldon SH, Spire JP, Levy HB. Pediatric sleep medicine. Philadelphia: W. B. Saunders; 1992.

4. Stein MA, Mendelsohn J, Obermeyer WH, Amromin J, Benca R. Sleep and behavior problems in school-aged children. Pediatrics. 2001;107:E60.

5. Gregory AM, O'Connor TG. Sleep problems in childhood: a longitudinal study of developmental change and association with behavioral problems. J Am Acad Child Adolesc Psychiatry. 2002;41:964-71.

6. American Sleep Disorders Association (ASDA). The international classification of sleep disorders, Revised. Rochester (MN): American Sleep Disorders Association; 1997.

7. Nunes ML. Distúrbios do sono. J Pediatr (Rio J). 2002;78:(Supl 1):S563-72. 
8. Archbold KH, Pituch KJ, Panahi P, Chervin RD. Symptoms of sleep disturbances among children at two general pediatric clinics. J Pediatr. 2002;140:97-102.

9. Estivill SE. Getting the child to sleep: critical review of 12 years of experience. An Esp Pediatr. 2002;56:35-9.

10. Richman N. Surveys of sleep disorders in children in a general population. In: Gulleminaut C, editor. Sleep and its disorders in children. Baltimore: Raven Press; 1987. p. 132-142.

11. Ferber R. Sleeplessness in children. In: Ferber R, Kryger M, editors. Principles and practice of sleep medicine in the child. Philadelphia: W. B. Saunders; 1995. p. 79-89.

12. DahI RE, Carskadon MA. Sleep and its disorders in adolescence. In: Ferber R, Kryger M, editors. Principles and practice of sleep medicine in the child. Philadelphia: W. B. Saunders; 1995. p. 19-27.

13. Wolfson AR. Sleeping patterns of children and adolescents, developmental trends, disruption and adaptations. Chil Adolesc Psychiatr Clin North Am. 1996;5:549-68.

14. Anders TF, Sadeh A, Apparedy V. Normal sleep in neonates and children. In: Ferber R, Kryger M, editors. Principles and practice of sleep medicine in the child. Philadelphia: W. B. Saunders; 1995. p. 7-18.

15. Kahn A, Dan B, Groswasser J, Franco P, Sottiaux M. Normal sleep architecture in infants and children. J Clin Neurophysiol. 1996;13:184-97.

16. Iglowstein I, Jenni OG, Molinari L, Largo RH. Sleep duration from infancy to adolescence: reference values and generational trends. Pediatrics. 2003;111:302-7.

17. Alves RS, Ejzenberg B, Okay Y. Revisão das desordens do sono com excessiva movimentação, insônia e sonolência na criança. Pediatria (São Paulo). 2002;24:50-64.

18. Madeira IR, Aquino LA. Problemas de abordagem difícil: "Não come", "não dorme". J Pediatr (Rio J). 2003;79 (Supl 1):S43-54.

19. Marcus CL. Obstructive sleep apnea syndrome: differences between children and adults. Sleep. 2000;23 (Suppl 4):S140-1.

20. Brown LH, Maistros P, Guilleminaut C. Sleep in children with neurologic problems. In: Ferber $R$, Kryger $M$, editors. Principles and practice of sleep medicine in the child. Philadelphia: W. B. Saunders; 1995. p. 135-145.

21. Johnson CR. Sleep problems in children with mental retardation and autism. Child Adolesc Psychiatr Clin North Am 1996;5:673-83.

22. Abril BV, Mendez MG, Sans OC, Valdizan JR. Sleep in infantile autism. Revue Neurologique. 2001;32:641-4.

23. Kohrman MH, Carney PR. Sleep-related disorders in neurologic disease during childhood. Pediatric Neurol. 2000;23:107-13.

24. Loughlin GM, Carrol JL. Sleep and respiratory disease in children. In: Ferber R, Kryger M, editors. Principles and practice of sleep medicine in the child. Philadelphia: W. B. Saunders; 1995. p. 217-230.

25. Kirk VG, Flemons WW, Adams C, Rimmer KP, Montgomery MD. Sleep-disordered breathing in Duchenne muscular dystrophy: a preliminary role of portable monitoring. Pediatr Pulmonol. 2000;29:135-40.

26. Nunes ML, Ferri R, Arzimanoglou A, Curzi L, Appel CC, da Costa JC. Sleep organization in children with partial refractory epilepsy. J Child Neurol. 2003;18:761-4.

27. Nunes ML. Avaliação da relação entre sono e epilepsia com enfoque especial na infância: aspectos clínicos e neurobiológicos. J Epilepsy Clin Neurophysiol. 2004;10 (Supl 2):S21-8.

28. Bauzano PE. Childhood insomnia. Rev Neurol. 2003;36:381-90.

29. Sadeh A. Stress, trauma and sleep in children. Child Adolesc Psychiatr Clin North Am. 1996;5:685-97.

30. Goodlin-Jones BL, Anders TF. Relationship disturbances and parent-child therapy: sleep problems. Child Adolesc Psychiatr Clin North Am. 2001;10:487-99.

31. Johnson EO, Chilcoat HD, Breslau N. Trouble sleeping and anxiety/depression in childhood. Psychiatry Res. 2000;94: 93-102.

32. Estivill E. Childhood insomnia due to disorderly habits. Rev Neurol. 2000;30:188-91.
33. Hayes MJ, Parker KG, Sallinen B, Davare AA. Bedsharing, temperament, and sleep disturbance in early childhood. Sleep. $2001 ; 24: 657-62$

34. Ferber R. Sleep schedule - dependent causes of insomnia and sleepiness in middle childhood and adolescence. Pediatrician. $1990 ; 17: 13-20$.

35. Louzada F, Menna-Barreto L. Relógios biológicos e aprendizagem. São Paulo: EDESPLAN; 2004

36. Glaze D. Childhood insomnia: why Chris can't sleep. Pediatr Clin North Am. 2004;51:33-50.

37. Kotagal S, Silber MH. Childhood - onset restless legs syndrome. Ann Neurol. 2004;56:803-7.

38. Ivanenko A, Crabtree VM, Gozal D. Sleep in children with psychiatric disorders. Pediatr Clin North Am. 2004;51:5-68.

39. Dias VR. Psicodrama: teoria e prática. São Paulo: Editora Agora; 1987.

40. Owens JA, Maxim R, Nobile C, McGuinn M, Msall M. Parental and self - report of sleep in children with attention - deficit/ hyperactive disorder. Arch Pediatr Adolesc Med. 2000;154: 549-55.

41. Rohde LA, Halpern R. Transtorno de déficit de atenção/ hiperatividade: atualização. J Pediatr (Rio J). 2004;80 (Supl 2): $561-70$.

42. Feikema WJ. Headache and chronic sleep deprivation. An often missed relationship in children and adults. Ned Tijjdschr Geneeskd. 1999;143:488-93.

43. Smeyers P. Headaches in childhood: association with sleep disorders and psychological implications. Rev Neurol. 1999;28 (Suppl 2):S150-55.

44. Meltzer LJ, Mindell JA. Nonpharmacologic treatments for pediatric sleeplessness. Pediatr Clin North Am. 2004;51:135-51.

45. France KG, Henderson JM, Hudson SM. Fact, act, and tact: a three stage approach to treating the sleep problems of infants and young children. Child Adolesc Psychiatr Clin North Am. 1996;5:581-99.

46. Stepanski EJ, Wyatt JK. Use of sleep hygiene in the treatment of insomnia. Sleep Med Rev. 2003;7:201-2.

47. Durand VM. Sleep better. Baltimore: Paul H. Brooks; 1998. p. 75-117.

48. Rickert VI, Johnson CM. Reducing nocturnal awakening and crying episodes infants and young children: a comparison between scheduled awakenings and systematic ignoring. Pediatrics. 1988;81:203-12.

49. Ramchandani $P$, Wigs $L$, Webb $V$, Stores $G$. A systematic review of treatments for settling problems and night-waking in young children. Br Med J. 2000;320:209-13.

50. Knapp P, Blaya DB. Conceitualização cognitiva: modelo de Beck. In: Caminha RM, Wainer R, Oliveira M, Picccoloto NM, editores. Psicoterapias cognitivo-comportamentais, teoria e prática. São Paulo: Casa do Psicólogo; 2003. p. 39-52.

51. Smith MT, Neubauer DN. Cognitive behavior therapy for chronic insomnia. Clin Cornerstone. 2003;5:28-40.

52. Edinger JD, Wohlgemuth WK, Radtke RA, Marsh GR, Quilian RE. Cognitive behavior therapy for treatment of chronic primary insomnia. JAMA. 2001;285:1856-64.

53. Practice Committee of the American Academy of Seep Medicine. Practice parameters for the nonpharmacologic treatment of chronic insomnia. Sleep. 1999;22:1128-33.

54. Muris P, Meesters C, van Melick M. Treatment of childhood anxiety disorders: a preliminary comparison. J Behav Ther Exp Psychiatry. 2002;33:143-58.

55. Feilstrecker N, Hatzenberger R, Caminha RM. Técnicas cognitivocomportmentais. In: Caminha RM, Wainer R, Oliveira M, Picccoloto NM, editors. Psicoterapias cognitivo-comportamentais, teoria e prática. São Paulo: Casa do Psicólogo; 2003. p. 54-60.

56. Pelayo R, Chen W, Monzon S, Guilleminaut C. Pediatric sleep pharmacology: you want to give my kid sleeping pills? Pediatr Clin North Am. 2004;51:117-34.

57. Idiazabal AM, Estivill SE. Treatment of insomnia in children: pharmacological aspects. An Pediatr (Barc). 2003;59:239-45. 
58. Attele AS, Xie JT, Yuan CS. Treatment of insomnia: an alternative approach. Altern Med Rev. 2000;5:249-59.

59. Jan JE, Espezel $H$, Appleton RE. The treatment of sleep disorders with melatonin. Rev Med Child Neurol. 1994;36:97-107.

60. Smits MG, Nagtegaal EE, van der Heijden J, Coenen AM, Kerkhof GA. Melatonin for chronic sleep onset insomnia in children: a randomized placebo-controlled trial. J Child Neurol. 2001;16: 86-92.

61. Gozal D, O'Brien LM. Neurocognitive dysfunction and sleep in children: from human to rodent. Pediatr Clin North Am. 2004;51:187-202.
Correspondence:

Magda Lahorgue Nunes

Serviço de Neurologia do Hospital São Lucas da PUCRS

Av. Ipiranga, 6.690/220

CEP 90610-000 - Porto Alegre, RS, Brazi

Tel./Fax: +55 (51) 3339.4936

E-mail: nunes@pucrs.br 